\title{
HUBUNGAN HARGA DAN PROMOSI DENGAN KEPUTUSAN PEMBELIAN KREDIT PEMILIKAN RUMAH (KPR) DI PT BANK MANDIRI JAKARTA KOTA
}

\author{
${ }^{1)}$ Mas Mochamad Deden Sukmana, ${ }^{2)}$ Sufrin Hannan, ${ }^{3)}$ Jan Horas V Purba \\ 1) Pasacasarjana Universitas Pakuan \\ Jl. Pakuan Tegellega, Bogor Tengah, Kota Bogor Jawa Barat, 16143, Indonesia \\ Email: bangdens09@gmail.com \\ 2) Pasacasarjana Universitas Pakuan \\ Jl. Pakuan Tegellega, Bogor Tengah, Kota Bogor Jawa Barat, 16143, Indonesia \\ Email: pasca@unpak.ac.id \\ 3) Pasacasarjana Universitas Pakuan \\ Jl. Pakuan Tegellega, Bogor Tengah, Kota Bogor Jawa Barat, 16143, Indonesia \\ Email: pasca@unpak.ac.id
}

\begin{abstract}
The purpose of this research is to find out and analyze to find out the relationship of promotion and price together with the purchase decision of KPR at PT Bank Mandiri Tbk Jakarta Kota. This research was carried out at the PT Bank Mandiri Tbk Jakarta Kota office. The results of the study show there is a positive and significant relationship between the price variable and the purchasing decision with the value of the correlation coefficient $(r)$ of 0.769 . There is a positive and significant relationship between promotional variables and purchasing decisions with a correlation coefficient (r) of 0.829. There is a positive and significant relationship between price and promotion variables together with purchasing decisions with a correlation coefficient $(r)$ of 0.914. Price contribution $\left(X_{1}\right)$ and promotion $\left(X_{2}\right)$ together towards purchasing decisions $(Y)$ are calculated based on the coefficient of determination or the value of Adjusted $R$ Square $\left(R^{2}\right) \times 100 \%$. Based on the results above, it is known that the Adjusted $R$ Square $\left(R^{2}\right)=0.833$ value. This shows that $83.3 \%$ of purchasing decisions are influenced by price and promotion while the remaining $16.7 \%$, purchase decisions are influenced by other factors which are not discussed in this study.
\end{abstract}

Keywords: Price, Promotion, Purchase Decision, PT Bank Mandiri Tbk Jakarta Kota

\begin{abstract}
ABSTRAK
Tujuan penelitian ini adalah untuk mengetahui dan menganalisa hubungan promosi dan harga secara bersama-sama dengan keputusan pembelian KPR pada PT Bank Mandiri Tbk Jakarta Kota. Penelitian ini dilaksanakan di Kantor PT Bank Mandiri Tbk Jakarta Kota Hasil penelitian menunjukkan Terdapat hubungan positif dan signifikan antara variabel harga dengan keputusan pembelian dengan nilai koefisien korelasi (r) sebesar 0,769. Terdapat hubungan positif dan signifikan antara variabel promosi dengan keputusan pembelian dengan nilai koefisien korelasi (r) sebesar 0,829. Terdapat hubungan positif dan signifikan antara variabel harga dan promosi secara bersama-sama dengan keputusan pembelian dengan nilai koefisien korelasi $(r)$ sebesar 0,914 . Kontribusi harga $\left(X_{1}\right)$ dan promosi $\left(X_{2}\right)$ secara bersama-sama terhadap keputusan pembelian (Y) dihitung berdasarkan nilai koefisien determinasi atau nilai Adjusted $R$ Square $\left(R^{2}\right)$ x $100 \%$. Berdasarkan hasil tersebut di atas diketahui nilai Adjusted $R$ Square $\left(R^{2}\right)=0,833$, Hal ini menunjukan bahwa 83,3\% keputusan pembelian dipengaruhi oleh harga dan promosi sedangkan sisanya $16,7 \%$, keputusan pembelian dipengaruhi oleh faktor lain yang dalam penelitian ini tidak dibahas.
\end{abstract}

Kata kunci: Harga, Promosi, Keputusan Pembelian, PT Bank Mandiri Tbk, Jakarta Kota

\begin{tabular}{lll}
\hline 1. PENDAHULUAN & dan sebagai tempat berkumpul dan \\
1.1 Latar Belakang & berlangsungnya aktivitas keluarga. Sekaligus \\
Rumah sebagai tempat tinggal adalah & sebagai sarana investasi. Fungsi rumah juga \\
salah satu kebutuhan pokok manusia selain & telah berubah, dari yang semula hanya sekedar \\
pakaian dan makanan. Setiap manusia & sebagai tempat berlindung. Pertumbuhan \\
membutuhkan rumah untuk tempat berlindung & penduduk yang semakin meningkat dan lahan
\end{tabular}


untuk pemukiman yang terbatas menjadikan masalah perumahan yang kompleks, selain itu harga rumah saat ini yang terus meningkat menyebabkan masyarakat sulit dan jarang yang mampu membeli rumah secara tunai. KPR merupakan jenis kredit yang memberikan fasilitas keuangan bagi masyarakat yang ingin membeli rumah dengan menjaminkan sertifikat dari rumah yang dibeli tersebut.

DKI Jakarta sebagai Ibukota Negara Indonesia merupakan magnet bagi masyarakat dari daerah luar Jakarta untuk mencoba peruntungan, tidak jarang orang yang sudah tinggal dan bekerja di Jakarta merasa sangat nyaman dan betah untuk hidup di Jakarta, sehingga berpikir untuk dapat memiliki hunian di Jakarta.

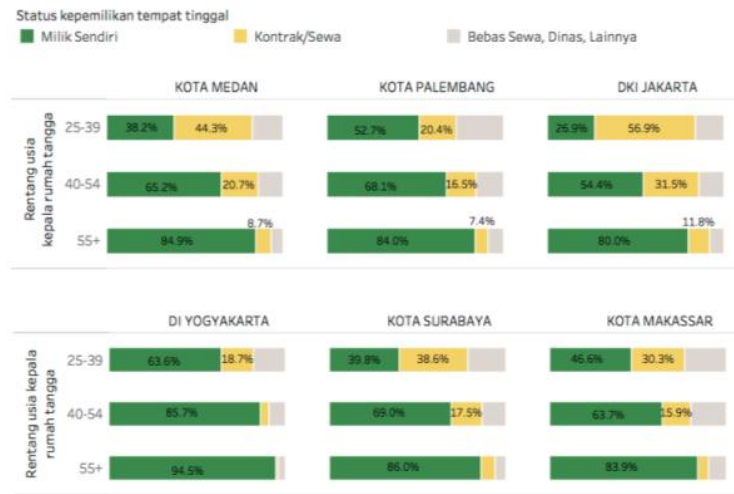

Data dari empat kota besar dan dua provinsi di Indonesia yakni, Medan, Palembang, Surabaya, Makassar, DKI Jakarta, dan DI Yogyakarta. Dibanding di DKI Jakarta, anak muda usia produktif di DI Yogyakarta lebih banyak yang bisa punya rumah. Rumah tangga milenial pada rentang usia 25-39 di Provinsi DI Yogyakarta yang punya rumah sendiri mencapai 63,6 persen. Sisanya sebanyak 18,7 persen masih tinggal di rumah sewa atau kontrak, dan lainnya tinggal di rumah bebas sewa. Sedangkan usia milenial yang berumah tangga di DKI Jakarta, hanya 26,9 persennya yang sudah tinggal di rumah sendiri. Paling banyak adalah para penyewa, dan sisanya berstatus rumah tinggal tak berbayar. (https://beritagar.id)

\subsection{Identifikasi Masalah}

Identifikasi masalah dalam penelitian ini meliputi:

1. Promosi produk KPR PT Bank Mandiri Tbk Jakarta Kota kurang maksimal.

2. Harga rumah dalam keputusan pembelian KPR di PT Bank Mandiri Tbk Jakarta Kota cenderung naik setiap tahunnya.

3. Biaya promosi kurang maksimal.

\subsection{Rumusan Masalah}

Rumusan masalah dalam penelitian ini adalah :

1. Apakah terdapat hubungan promosi dengan keputusan pembelian KPR pada PT Bank Mandiri Tbk Jakarta Kota?

2. Apakah terdapat hubungan harga dengan keputusan pembelian KPR pada PT Bank Mandiri Tbk Jakarta Kota?

3. Apakah terdapat hubungan promosi dan harga secara simultan dengan keputusan pembelian KPR pada PT Bank Mandiri Tbk Jakarta Kota?

\subsection{Tujuan Penelitian}

Tujuan penelitian dalam penelitian ini adalah :

1. Untuk mengetahui hubungan promosi dengan keputusan pembelian KPR pada PT Bank Mandiri Tbk Jakarta Kota.

2. Untuk mengetahui hubungan harga dengan keputusan pembelian KPR pada PT Bank Mandiri Tbk Jakarta Kota.

3. Untuk mengetahui hubungan promosi dan harga secara bersama-sama dengan keputusan pembelian KPR pada PT Bank Mandiri Tbk Jakarta Kota.

\section{TINJAUAN PUSTAKA}

\subsection{Hakikat Keputusan Pembelian}

Schiffman dan Kanuk (2009 : 112), keputusan pembelian yaitu pemilihan dari dua atau lebih alternatif pilihan keputusan pembelian, artinya bahwa seseorang bisa 
membuat keputusan, harus tersedia beberapa alternatif pilihan. Dari pengertian dan definisi dari para ahli di atas maka dapat disintesiskan bahwa pengambilan keputusan konsumen adalah proses pengintegrasian yang mengkombinasikan pengetahuan untuk mengevaluasi dua atau lebih perilaku alternatif, dan memilih salah satu diantaranya. Indikator keputusan pembelian adalah:

1. Kebudayaan,

2. Kelas sosial,

3. Keluarga,

4. Pengalaman,

5. Kepribadian,

6. Sikap dan kepercayaan, dan

7. Konsep diri.

\subsection{Hakikat Harga}

Menurut Kotler dan Armstrong (2014:313) menerangkan bahwa definisi harga adalah jumlah yang harus disiapkan oleh pelanggan yang ingin mendapatkan barang atau jasa atau jumlah dari nilai yang ditukar konsumen atas manfaat-manfaat karena memiliki atau menggunakan produk atau jasa tersebut.

Disisi lain Kotler (2008 : 345) menyatakan bahwa indikator yang mencirikan harga adalah sebagai berikut :

1. Keterjangkauan harga.

2. Kesesuaian harga dengan kualitas produk.

3. Daya saing harga.

4. Kesesuaian harga dengan manfaat produk.

5. Harga mempengaruhi daya beli konsumen.

6. Harga dapat mempengaruhi konsumen dalam mengambil keputusan.

Berdasarkan pendapat ahli di atas maka sintesis dari harga adalah sejumlah uang yang dibayar untuk sebuah produk atau jasa atau sejumlah nilai yang harus ditukar konsumen untuk keuntungan yang telah dipakai atau digunakan dari sebuah produk atau jasa.

Indikator kinerja dalam penelitian ini adalah :

1. Keterjangkauan harga,

2. Kesesuaian harga dengan kualitas produk,
3. Daya saing harga, dan

4. Kesesuaian harga dengan manfaat produk.

\subsection{Hakikat Promosi}

Menurut Assauri (2011 : 264), promosi merupakan kegiatan yang dilakukan untuk mempengaruhi nasabah untuk menciptakan permintaan atas suatu produk /jasa. Berdasarkan pendapat ahli diatas maka sintesis dari promosi merupakan kegiatan yang dilakukan untuk mempengaruhi nasabah untuk menciptakan permintaan atas suatu produk /jasa".

Indikator promosi dalam penelitian ini yaitu :

1. Periklanan (Advertising),

2. Promosi Penjualan (Sales Promotion),

3. Publisitas (Pubilicity)

4. Penjualan Pribadi (Personal Selling).

\subsection{Penelitian Yang Relevan}

1. Penelitian Lili Ekawati, H.Eddy Soegiarto, Eka Yudhyani.

Penelitian ini berjudul "Pengaruh Harga Dan Promosi Terhadap Keputusan Membeli Air Mineral Aqua Di Samarinda". Hasil penelitian ditunjukkan pengaruh produk, harga dan promosi terhadap keputusan membeli air mineral merek Aqua secara parsial berpengaruh positif dan signifikan terhadap keputusan membeli di Samarinda.

2. Penelitian Ahmad Muanas, tahun 2014. Penelitian ini berjudul "Pengaruh Produk, Harga Dan Promosi Terhadap Keputusan Pembelian Mobil Buana Indomobil Trada. Hasil pengujian menunjukkan pengaruh variabel produk, harga, dan promosi terhadap keputusan pembelian mobil Suzuki di PT. Buana Indomobil Trada Surabaya adalah signifikan. Hasil ini mengindikasikan bahwa model yang digunakan dalam penelitian tersebut layak untuk dilakukan analisis berikutnya. Hasil ini didukung dengan perolehan tingkat 
koefisien korelasi sebesar 71,2\% menunjukkan korelasi atau hubungan antara variabel tersebut terhadap keputusan pembelian mobil Suzuki di PT. Buana Indomobil Trada Surabaya memiliki hubungan yang erat.

\subsection{Kerangka Pemikiran}

\subsubsection{Hubungan Harga Dengan Keputusan Pembelian.}

Harga adalah sejumlah nilai yang ditukarkan konsumen dengan manfaat dari memiliki dan menggunakan produk atau jasa yang ditetapkan oleh pembeli atau penjual untuk suatu harga yang sama terhadap semua pembeli. Dalam menentukan keputusan pembelian seorang konsumen akan mempertimbangkan harga yang ditawarkan oleh penyedia jasa/barang. Berdasarkan uraian di atas maka diduga terdapat hubungan antara harga dengan keputusan pembelian.

\subsubsection{Hubungan Promosi Dengan} Keputusan Pembelian.

Dalam tahap evaluasi, para konsumen membentuk preferensi atas produk barang /jasa yang ada di dalam kumpulan pilihan. Konsumen tersebut juga dapat membentuk niat untuk membeli produk yang paling disukai berdasarkan promosi yang ditawarkan. Berdasarkan uraian di atas maka diduga terdapat hubungan antara promosi dengan keputusan pembelian.

\subsubsection{Hubungan Harga Dan Promosi} Secara Bersama-Sama Dengan Keputusan Pembelian.

Promosi yang dilakukan dapat beruba apa saja, salah satunya yaitu melalui penetapan harga. Jika promosi dilakukan dengan baik dan maksimal maka akan menjadi pertimbagan konsumen dalam memutuskan pembelian. Dalam tahap evaluasi, para konsumen membentuk preferensi atas produk barang/jasa yang ada di dalam kumpulan pilihan. Konsumen tersebut juga dapat membentuk niat untuk membeli produk yang paling disukai berdasarkan tidak hanya promosi yang ditawarkan, tetapi juga harga yang ditetapkan. Berdasarkan uraian di atas maka diduga terdapat hubungan antara promosi dan harga secara bersama-sama dengan keputusan pembelian.

\subsection{Hipotesis Penelitian}

Berdasarkan landasan teori yang dikemukakan diatas, maka hipotesis yang diajukan dalam penelitian ini adalah :

1. Diduga terdapat pengaruh harga terhadap keputusan pembelian KPR di PT Bank Mandiri Tbk Jakarta Kota.

2. Diduga terdapat pengaruh promosi terhadap keputusan pembelian KPR di PT Bank Mandiri Tbk Jakarta Kota.

3. Diduga terdapat pengaruh promosi dan harga secara simultan terhadap keputusan pembelian KPR di PT Bank Mandiri Tbk Jakarta Kota.

\section{METODE PENELITIAN}

\subsection{Tempat dan Waktu Penelitian}

Penelitian dilaksanakan di Kantor PT Bank Mandiri Tbk Jakarta Kota. Waktu penelitian adalah selama 6 bulan yaitu dimulai dari bulan Juni sampai dengan Nopember 2018.

\subsection{Metode Penelitian}

Dalam penelitian ini, menggunakan penelitian kuantitatif korelasional. Jenis penelitian ini adalah salah satu teknik statistik yang digunakan untuk mencari hubungan antara dua variabel atau lebih yang sifatnya kuantitatif Atas dasar tinjauan landasan teori dan penelitian terdahulu maka dalam penelitian ini, konstelasi variabel penelitian dapat digambarkan seperti berikut ini:

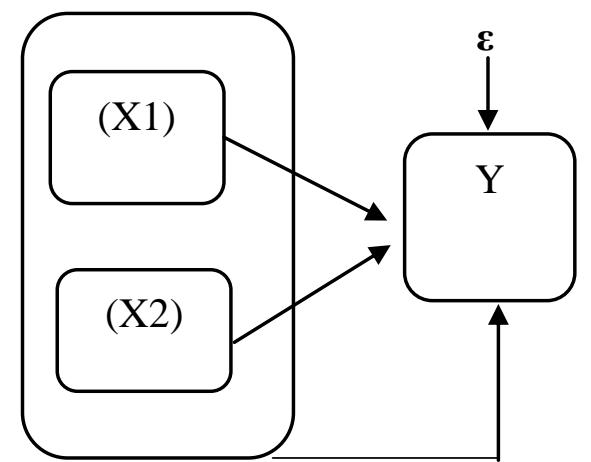


Gambar 1. Konstelasi Variabel Tahap Penelitian

Keterangan:

$\mathrm{X} 1$ = Harga

$\mathrm{X} 2$ = Promosi

$\mathrm{Y}=$ Keputusan Pembelian

$\varepsilon \quad=$ Variabel lain yang tidak diteliti

\subsection{Populasi dan Sampel}

Dalam penelitian ini jumlah populasinya adalah 195 Nasabah di PT Bank Mandiri Tbk Jakarta Kota yang mengambil KPR dalam 6 bulan terakhir Dalam penelitian ini pengambilan sampel di lakukan dengan metode Convenience Sampling di mana data yang di ambil berdasarkan kemudahan saja (Sulistyo. 2012). Jumlah sampel dalam penelitian ini di tentukan dengan menggunakan rumus Slovin. Berikut ini adalah perhitungannya:

$$
\begin{aligned}
\mathrm{n} & =\frac{195}{1+195(5 \%)^{2}} \\
& =\frac{195}{1,48} \\
& =131,09
\end{aligned}
$$

Dalam penelitian ini sampel yang diambil berjumlah 132 responden.

\subsection{Teknik Pengumpulan Data}

Teknik pengumpulan data dalam penelitian merupakan metode atau cara yang digunakan oleh peneliti untuk mendapatkan data dalam suatu penelitian. Tehnik pengumpulan data dalam penelitian ini menggunakan metode kuesioner.

\begin{tabular}{|c|c|c|c|c|}
\hline \multirow[t]{2}{*}{ No } & \multirow[t]{2}{*}{ Indikator } & \multicolumn{2}{|c|}{$\begin{array}{c}\text { Jumlah } \\
\text { Pertanyaan }\end{array}$} & \multirow{2}{*}{$\begin{array}{c}\text { Jmlh } \\
\text { Butir } \\
\text { Soal }\end{array}$} \\
\hline & & Positif & Negatif & \\
\hline 1 & $\begin{array}{l}\text { Keterjangkauan } \\
\text { harga }\end{array}$ & 8 & 2 & 10 \\
\hline 2 & $\begin{array}{l}\text { Kesesuaian } \\
\text { harga dengan } \\
\text { kualitas }\end{array}$ & 8 & 2 & 10 \\
\hline
\end{tabular}

\subsection{Instrumen Penelitian Variabel}

Tabel 1. Kisi-kisi Harga (X1)

\begin{tabular}{|c|l|c|c|c|}
\hline 3 & Daya saing & 8 & 2 & 10 \\
\hline 4 & $\begin{array}{l}\text { Kesesuaian dgn } \\
\text { manfaat }\end{array}$ & 8 & 2 & 10 \\
\hline \multicolumn{2}{|c|}{ Total Jumlah Butir } & $\mathbf{3 2}$ & $\mathbf{8}$ & 40 \\
\hline
\end{tabular}

Tabel 2. Kisi-kisi Variabel Promosi (X2)

\begin{tabular}{|c|l|c|c|c|}
\hline \multirow{2}{*}{ No } & Indikator & \multicolumn{2}{|c|}{ Butir Soal } & Jumlah \\
\cline { 3 - 4 } & Positif & Negatif & $\begin{array}{c}\text { Butir } \\
\text { Soal }\end{array}$ \\
\hline 1 & Periklanan & 8 & 2 & 10 \\
\hline 2 & $\begin{array}{l}\text { Promosi } \\
\text { penjualan }\end{array}$ & 8 & 2 & 10 \\
\hline 3 & Publisitas & 8 & 2 & 10 \\
\hline 4 & $\begin{array}{l}\text { Penjualan } \\
\text { pribadi }\end{array}$ & 8 & 2 & 10 \\
\hline \multicolumn{2}{|l}{ Total Jumlah Butir } & $\mathbf{3 3}$ & $\mathbf{8}$ & 40 \\
\hline
\end{tabular}

\begin{tabular}{|c|c|c|c|c|}
\hline \multirow{2}{*}{ No } & \multirow{2}{*}{ Indikator } & \multicolumn{2}{|c|}{ Butir Soal } & \multirow{2}{*}{$\begin{array}{c}\text { Jumlah } \\
\text { Butir } \\
\text { Soal }\end{array}$} \\
\hline & & Positif & Negatif & \\
\hline 1 & Kebudayaan & 5 & 1 & 6 \\
\hline 2 & Kelas Sosial & 5 & 1 & 6 \\
\hline 3 & Keluarga & 5 & 1 & 6 \\
\hline 4 & Pengalaman & 5 & 1 & 6 \\
\hline 5 & Kepribadian & 5 & 1 & 6 \\
\hline 6 & Sikap & 4 & 1 & 5 \\
\hline \multirow[t]{2}{*}{7} & Konsep diri & 4 & 1 & 5 \\
\hline & $\begin{array}{l}\text { Total Jumlah } \\
\text { Butir }\end{array}$ & 33 & 7 & 40 \\
\hline
\end{tabular}

Tabel 3. Kisi-kisi Variabel Keputusan Pembelian (Y)

\subsection{Uji Coba}

\subsubsection{Pengujian Validitas}

Uji validitas dihitung dengan membandingkan nilai $\mathrm{r}$ hitung (correlated item-total correlation)dengan nilai $r$ tabel. Jika $\mathrm{r}$ hitung $>\mathrm{r}$ tabel dan nilai positif maka butir atau pertanyaan tersebut dinyatakan valid (Ghozali, 2005 : 45).

\subsubsection{Pengujian Reliabilitas}

Suatu konstruk atau variabel dikatakan reliable jika memberikan nilai Cronbach Alpha $>$ 0,60 (Ghozali, 2005:46). 


\subsection{Teknik Analisa Data}

\subsubsection{Uji Persyaratan Analisis}

Uji persyaratan analisis yang digunakan dalam penelitian ini terdiri dari:

a. Uji Normalitas

\subsubsection{Uji Hipotesis Data Statistik}
a. Uji Regresi Linier Berganda
b. Uji Korelasi Sederhana
c. Uji Korelasi Berganda
d. Uji Koefisien Determinasi
e. Analisis Korelasi Parsial

\section{HASIL DAN PEMBAHASAN}

\subsection{Pengujian Hipotesis}

Tabel 4. Hubungan Harga (X1) dengan Keputusan Pembelian (Y)

Model Summary ${ }^{\mathrm{b}}$

\begin{tabular}{|l|l|r|r|r|}
\hline Model & \multicolumn{1}{|c|}{$\mathrm{R}$} & $\begin{array}{c}\mathrm{R} \\
\text { Square }\end{array}$ & $\begin{array}{r}\text { Adjusted } \\
\text { R Square }\end{array}$ & $\begin{array}{c}\text { Std. Error of } \\
\text { the Estimate }\end{array}$ \\
\hline 1 & $.769^{\mathrm{a}}$ &, 592 &, 589 & 5,25386 \\
\hline
\end{tabular}

a. Predictors: (Constant), Harga

b. Dependent Variable: KeputusanPembelian Sumber : Data primer yang diolah, 2018

Nilai koefisien korelasi (r) sebesar 0,769, hal ini menunjukkan bahwa hubungan harga dengan keputusan pelanggan berada pada kriteria hubungan yang kuat sebesar 0,769. Kontribusi harga $\left(\mathrm{X}_{1}\right)$ terhadap keputusan pembelian (Y) dihitung berdasarkan nilai koefisien determinasi atau nilai $R$ Square $\left(\mathrm{R}^{2}\right)$ $\mathrm{x} 100 \%$. Berdasarkan hasil tersebut di atas diketahui nilai $R$ Square $=0,592 \mathrm{Hal}$ ini berarti bahwa harga $\left(\mathrm{X}_{1}\right)$ membentuk kontribusi sebesar $5,92 \%$ terhadap keputusan pembelian (Y).

Tabel 5. Hubungan Fungsional Harga (X1) Terhadap Keputusan Pembelian (Y)

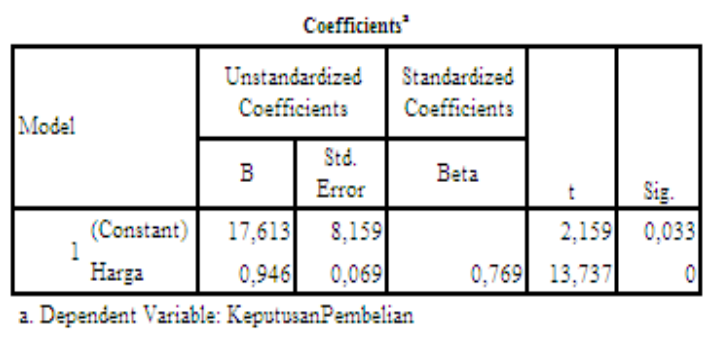

Sumber : Data primer yang diolah, 2018

Tabel 6. Hubungan Promosi (X2) Dengan Keputusan Pembelian (Y)

\begin{tabular}{|l|r|r|r|r|}
\hline \multicolumn{7}{|c|}{ Model Summary $^{\text {b }}$} \\
Mode & & & Adjuste \\
1 & $\mathrm{R}$ & $\mathrm{R}$ Square & $\begin{array}{c}\text { Std. } \\
\text { Error of } \\
\text { Square } \\
\text { the } \\
\text { Estimate }\end{array}$ \\
\hline 1 & $.829^{\mathrm{a}}$ &, 688 &, 686 & 4,59478 \\
\hline
\end{tabular}

a. Predictors: (Constant), Promosi

b. Dependent Variable: KeputusanPembelian Sumber : Data primer yang diolah, 2018

Nilai koefisien korelasi (r) sebesar 0,829, hal ini menunjukkan bahwa hubungan promosi dengan keputusan pembelian berada pada kriteria hubungan sangat kuat sebesar 0,829. Kontribusi promosi $\left(\mathrm{X}_{2}\right)$ terhadap keputusan pembelian (Y) dihitung berdasarkan nilai koefisien determinasi atau nilai $R$ Square $\left(\mathrm{R}^{2}\right)$ $\mathrm{x} 100 \%$. Berdasarkan hasil tersebut di atas diketahui nilai $R$ Square $=0,688$, Hal ini berarti bahwa promosi $\left(\mathrm{X}_{2}\right)$ membentuk kontribusi sebesar $68,8 \%$ terhadap keputusan pembelian (Y).

Tabel 7. Hubungan Fungsional Promosi (X2) Terhadap Keputusan Pembelian (Y)

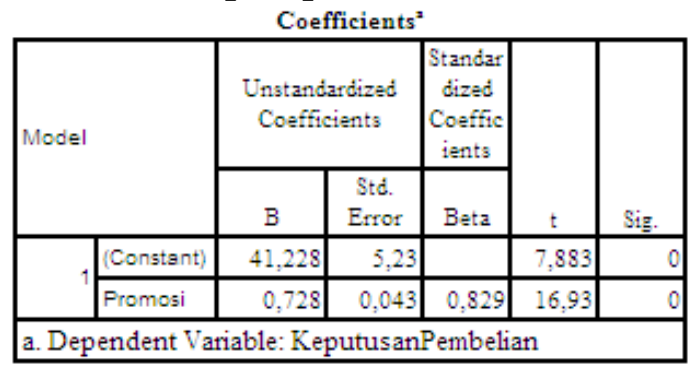

Sumber : Data primer yang diolah, 2018

Berdasarkan uji regresi seperti yang terlihat pada tabel di atas diperoleh persamaan regresi sebagai berikut: $\mathrm{Y}=41,228+0,728 \mathrm{X}$. 
Tabel 8. Hubungan Harga (X1) dan Promosi (X2) Secara Bersama-sama dengan Keputusan Pembelian (Y)

Model Summary ${ }^{\mathrm{b}}$

\begin{tabular}{|l|c|r|r|c|}
\hline Model & $\mathrm{R}$ & $\begin{array}{c}\mathrm{R} \\
\text { Square }\end{array}$ & $\begin{array}{c}\text { Adjusted } \\
\mathrm{R} \\
\text { Square }\end{array}$ & $\begin{array}{c}\text { Std. Error } \\
\text { of the } \\
\text { Estimate }\end{array}$ \\
\hline 1 & $.914^{\mathrm{a}}$ &, 836 &, 833 & 3,34631 \\
\hline
\end{tabular}

a. Predictors: (Constant), Harga, Promosi

b. Dependent Variable:KeputusanPembelian Sumber : Data primer yang diolah, 2018

Nilai koefisien korelasi (r) sebesar 0,914, hal ini menunjukkan bahwa hubungan harga $\left(\mathrm{X}_{1}\right)$ dan promosi $\left(\mathrm{X}_{2}\right)$ secara bersama-sama dengan keputusan pembelian berada pada kriteria hubungan yang sangat kuat sebesar 0,914. Kontribusi harga $\left(\mathrm{X}_{1}\right)$ dan promosi $\left(\mathrm{X}_{2}\right)$ secara bersama-sama terhadap keputusan pembelian (Y) dihitung berdasarkan nilai koefisien determinasi atau nilai Adjusted $R$ Square $\left(R^{2}\right)$ x 100\%. Berdasarkan hasil tersebut di atas diketahui nilai Adjusted $R$ Square $\left(R^{2}\right)=0,833$, Hal ini menunjukan bahwa $83,3 \%$ keputusan pembelian dipengaruhi oleh harga dan promosi sedangkan sisanya $16,7 \%$, keputusan pembelian dipengaruhi oleh faktor lain yang dalam penelitian ini tidak dibahas.

Tabel 9. Hubungan Fungsional Harga (X1) dan Promosi (X2) Secara Bersama-sama dengan Keputusan Pembelian (Y)

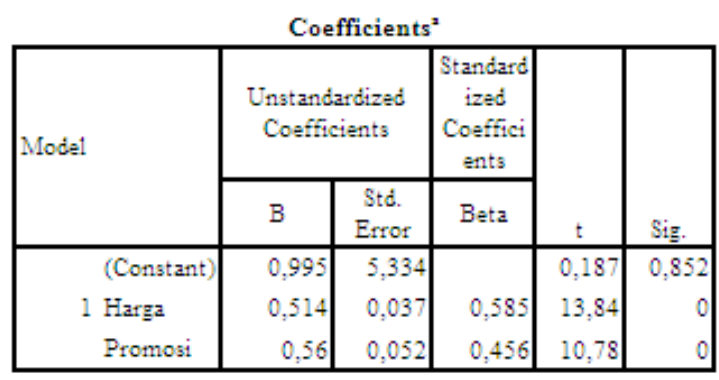

a. Dependent Variable: KeputusanPembelian

Sumber : Data primer yang diolah, 2018

Berdasarkan hasil uji regresi linear berganda seperti tampak pada tabel di atas diperoleh persamaan regresi yaitu: $\mathrm{Y}=0,995+$ $0,514 X_{1}+0,560 X_{2}$

Tabel 10. Hasil Uji Hipotesis Keberartian Model Hubungan Fungsional Antara Harga $\left(X_{1}\right)$ dan Promosi $\left(X_{2}\right)$ Secara bersama-sama dengan Keputusan Pembelian (Y)

\begin{tabular}{|c|c|c|c|c|c|}
\hline \multicolumn{6}{|c|}{ ANOVA $^{2}$} \\
\hline Model & $\begin{array}{l}\text { Sum of } \\
\text { Squares }\end{array}$ & $d f$ & Mean Square & F & Sig. \\
\hline 1 Regression & 22690,677 & 2 & 11345,338 & 310,139 & $000^{\circ}$ \\
\hline Residua! & 5194,565 & 142 & 36,581 & & \\
\hline Total & 27885,241 & 144 & & & \\
\hline
\end{tabular}

Sumber : Data primer yang diolah, 2018

Berdasarkan tabel ANOVA di atas di peroleh nilai $\mathrm{F}$ hitung sebesar 328,299 dengan nilai Siq.0,000. Sedangkan nilai F table untuk sampel yang berjumlah 132 dengan taraf signifikansi $5 \% \quad(0,05)$ adalah 2,673. Berdasarkan ketentuan hipotesis bahwa Ho ditolak dan Ha diterima jika nilai $\mathrm{F}$ hitung $>\mathrm{F}$ table dengan signifiansi $<0,05$. Dengan demikian hasil perhitungan tersebut menunjukkan bahwa nilai $\mathrm{F}$ hitung $(328,299)$ $>\mathrm{F}$ table $(2,673)$. Hal ini berarti membuktikan persamaan regresi di atas signifikan dengan variabel harga dan promosi dapat dipergunakan untuk memprediksi keputusan pembelian.

\subsection{Uji Korelasi Parsial}

Tabel 11. Hubungan Harga $\left(X_{1}\right)$ dengan Keputusan Pembelian (Y) dikendalikan oleh Promosi $\left(\mathbf{X}_{2}\right)$

\begin{tabular}{|lll|r|r|}
\hline \multicolumn{7}{|c|}{ Correlations } \\
\hline & & $\begin{array}{c}\text { Keputu } \\
\text { san } \\
\text { Pembel } \\
\text { ian }\end{array}$ & Harga \\
\hline \begin{tabular}{lll|r|} 
Control Variables \\
mos
\end{tabular} & Keputusan & Correlation & 1,000 &, 688 \\
$\mathrm{i}$ & Pembelian & Significance & &, 000 \\
& & (2-tailed) & & 129 \\
\cline { 2 - 5 } & Harga & Correlation &, 688 & 1,000 \\
& & Significance &, 000 & \\
& & (2-tailed) & 129 & 0 \\
\hline
\end{tabular}


Sumber : Data primer yang diolah, 2018

Berdasarkan jumlah sampel dalam penelitian ini (132 sampel) dan degrees of freedom (df atau derajat kebebasan) yaitu: $\mathrm{df}=$ $\mathrm{N}-\mathrm{k}-1$, artinya $\mathrm{N}=132, \mathrm{k}=$ jumlah variabel, maka df $=132-2-1=129$. Pada taraf signifikan 0,05 diperoleh nilai $r$ table sebesar 0.172 , dan nilai significance (2-tailed) $<0.05$. Karena nilai $0.688>0.172$ dan nilai signifikan $0.000<$ 0.05 , Hal ini menunjukkan bahwa korelasi atau hubungan variabel harga $\left(\mathrm{X}_{1}\right)$ dengan keputusan pembelian (Y) pada saat dikendalikan oleh variabel promosi $\left(\mathrm{X}_{2}\right)$ berada pada kriteria kuat.

Tabel 12. Hubungan Promosi $\left(\mathrm{X}_{2}\right)$ dengan Keputusan Pembelian (Y) dikendalikan oleh Harga $\left(\mathbf{X}_{1}\right)$

Correlations

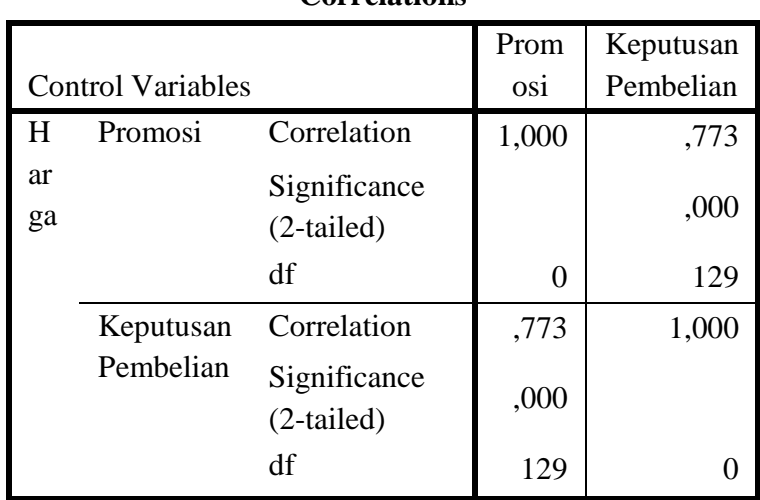

Sumber : Data primer yang diolah, 2018

Berdasarkan jumlah sampel dalam penelitian ini (132 sampel) dan degrees of freedom (df atau derajat kebebasan) yaitu: $\mathrm{df}=$ $\mathrm{N}-\mathrm{k}-1$, artinya $\mathrm{N}=132, \mathrm{k}=$ jumlah variabel, maka df $=132-2-1=129$. Pada taraf signifikan 0,05 diperoleh nilai $r$ table sebesar 0.172 , dan nilai significance (2-tailed) $<0.05$. Karena nilai $0.773>0.172$ dan nilai signifikan $0.000<$ 0.05, Hal ini menunjukkan bahwa korelasi atau hubungan variable promosi $\left(\mathrm{X}_{2}\right)$ dengan keputusan pembelian (Y) pada saat dikendalikan oleh variabel harga $\left(\mathrm{X}_{2}\right)$ berada pada kriteria kuat. Dengan demikian hasil perhitungan di atas dapat dijelaskan bahwa tingkat keeratan hubungan antara promosi dengan keputusan pembelian saat dikendalikan oleh harga adalah hubungannya kuat.

\subsection{Hubungan antar Dimensi Penelitian}

Berikut ini adalah rekapitulasi hasil matrik hubungan antar dimensi penelitian.

Tabel 13. Matrik Hubungan antar Dimensi Variabel Penelitian

\begin{tabular}{|c|c|c|c|c|c|c|c|}
\hline $\begin{array}{c}\text { Indika } \\
\text { tor }\end{array}$ & Y1 & Y2 & Y3 & Y4 & Y5 & Y6 & Y7 \\
\hline \multirow{2}{*}{ X11 } & ,49 & ,69 & ,20 & ,61 & ,35 & 45 & ,35 \\
\hline & $7^{* *}$ & $8^{* * *}$ & $4^{*}$ & $1^{* *}$ & $3^{* *}$ & $9^{* *}$ & $1^{* * *}$ \\
\hline \multirow[b]{2}{*}{ X12 } & ,62 & ,49 & ,24 & ,74 & ,08 & ,62 & ,49 \\
\hline & $4^{* *}$ & $9^{* * *}$ & $8^{* *}$ & $2^{* *}$ & 4 & $8^{* *}$ & $3^{* * *}$ \\
\hline \multirow{2}{*}{ X13 } & ,30 & ,29 & ,53 &, 35 & ,10 & 01 & ,08 \\
\hline & $1^{* *}$ & $8^{* *}$ & $9^{* * *}$ & $2^{* *}$ & 4 & 4 & 4 \\
\hline \multirow{2}{*}{ X14 } & ,21 & ,48 & ,95 & ,54 & ,04 & 01 & ,06 \\
\hline & $3^{*}$ & $6^{* *}$ & $2^{* *}$ & $7^{* *}$ & 2 & 6 & 1 \\
\hline \multirow{2}{*}{ X21 } & ,03 & ,01 &, 10 & 01 & ,24 & ,10 & ,07 \\
\hline & 6 & 7 & 2 & 4 & $1^{* *}$ & 5 & 6 \\
\hline \multirow[b]{2}{*}{$\mathrm{X} 22$} & 65 & ,40 & ,12 & ,60 & ,16 & ,69 & ,53 \\
\hline & $7^{* *}$ & $9^{* *}$ & 2 & $7^{* *}$ & 8 & $3^{* *}$ & $6^{* *}$ \\
\hline \multirow{2}{*}{$\mathrm{X} 23$} & ,33 & ,79 & ,18 & ,58 & ,51 & ,23 & ,20 \\
\hline & $6^{* *}$ & $8^{* *}$ & $5^{*}$ & $7^{* *}$ & $3^{* *}$ & $8^{* *}$ & $3^{*}$ \\
\hline \multirow{2}{*}{ X24 } & ,08 & ,02 &, 15 & ,05 & ,58 & ,46 & ,55 \\
\hline & 6 & 1 & 0 & 4 & $1^{* *}$ & $5^{* *}$ & $3^{* * *}$ \\
\hline
\end{tabular}

Sumber : Data primer yang diolah, 2018

Berdasarkan hasil matrik antar dimensi di atas diketahui bahwa nilai korelasi terbesar adalah dimensi X14 dengan Y3 sebesar 0,952 yang berarti keeratan hubungan antar dua dimensi tersebut sangat kuat. Kemudian nilai terbesar kedua adalah korelasi antara dimensi (X23) dengan (Y2) sebesar 0.798 yang berarti keeratan atau hubungan antar dimensi tersebut juga tergolong kuat.

\section{KESIMPULAN DAN SARAN}

\subsection{Kesimpulan}

Berdasarkan hasil penelitian yang telah dijelasakan pada bab sebelumnya maka dalam penelitian ini diperoleh beberapa kesimpulan antara lain:

1. Terdapat hubungan positif dan signifikan antara variabel harga dengan keputusan pembelian dengan nilai koefisien korelasi (r) sebesar 0,769,

2. Terdapat hubungan positif dan signifikan antara variabel promosi dengan keputusan 
pembelian dengan nilai koefisien korelasi (r) sebesar 0,829,

3. Terdapat hubungan positif dan signifikan antara variabel harga dan promosi secara bersama-sama dengan keputusan pembelian dengan nilai koefisien korelasi (r) sebesar 0,914.

\subsection{Saran}

Berdasarkan hasil penelitian dapat diberikan saran-saran sebagai berikut:

1. Variabel promosi yang terbukti paling dominan berpengaruh terhadap keputusan pembelian, sebaiknya pihak manajemen/perusahaan terus mempertahankan kegiatan promosi yang sudah ada demi meningkatkan keputusan pembelian.

2. Variabel harga yang dalam penelitian ini terbukti berkontribusi lebih kecil terhadap keputusan pembelian, sebaiknya pihak manajemen/perusahaan lebih meningkatkan harga secara maksimal, misalnya dengan memberikan diskon atau potongan harga.

3. Untuk penelitian di masa yang akan datang sebaiknya dicari variabel-variabel lain yang sekiranya mempengaruhi keputusan pembelian selain harga dan promosi.

\section{DAFTAR PUSTAKA}

Alma, Buchari. 2011. Manajemen Pemasaran dan Pemasaran Jasa. Bandung : Penerbit Alfabeta.

Amirullah.2002. Perilaku Konsumen. Graha Ilmu : Yogyakarta

Augusty, Ferdinand. 2006. Metode Penelitian Manajemen: Pedoman Penelitian untuk skripsi, Tesis dan Disertai Ilmu Manajemen. Semarang: Universitas Diponegoro

Assauri, Sofjan. 2011. "Strategic Management, Sustainable Competitive Advantage".Indonesia, Jakarta.
Buchari Alma. 2011, Manajemen Pemasaran dan Pemasaran Jasa. Edisi Keenam.Alfabeta. Bandung.

Boyd, et. al. 2010. Manajemen Pemasaran; Suatu Pendekatan Strategis dengan. Orientasi Global. Erlangga.

Boone, Louis E. Kurtz, David L. 2012. Pengantar Bisnis Kontemporer, buku 1. Jakarta: Salemba Empat

Dick Arya Tresnanda Zainul Arifin, 2014 "Sunarti Pengaruh Bauran Pemasaran Terhadap Keputusan Pembelian Rumah (Survei pada Konsumen Perumahan Blu Kid Residence Sidoarjo) Fakultas Ilmu AdministrasiUniversitas

BrawijayaMalang

Ghozali, Imam. 2005. Aplikasi Analisis Multivariate dengan Program SPSS. Badan Penerbit UniversitasDiponegoro. Semarang.

Hurriyati, Ratih. (2010). Bauran Pemasaran Dan Loyalitas Konsumen. Bandung: ALFABETHA.

Harini. 2008. Penetapan Harga ,Makro Ekonomi Pengantar, Pt Gramedia.

Jumiati dan Emilia, 2017 Pengaruh Harga Terhadap Keputusan KonsumenMembeli Rumah Tipe 36 Pada CV. Perdana LajuMandiri Di Guntung Manggis Kota Banjarbaru Fakutas Ekonomi Universitas Achmad Yani Banjarmasin

Kismono, Gugup. 2011. Bisnis Pengantar. Yogyakarta: BPFE-Yogyakarta.

Kotler, Philip, 2010. Manajemen Pemasaran: Analisis perencanaan, Implementasi dan pengendalian ( Edisi Kedua). Erlangga: Jakarta

2005. Manajemen Pemasaran, Erlangga: Jakarta . 2009. Manajemen Pemasaran, Analisis Perencanaan, Pengendalian. Jakarta : Erlangga.

Kotler, P \& Armstrong. 2010. Principles of Marketing, thirteen edition. New Jersey: Prentice-Hall, Inc.

Kotler dan Keller. 2009. Manajemen Pemasaran. Jilid I. Edisi ke 13. Jakarta: Erlangga. 
Kuat Supriyono, Leonardo Budi Hasiolan, Moh Mukery Warso tahun 2014. Pengaruh Produk, Harga Dan Promosi Terhadap Keputusan Konsumen Dalam Membeli Rumah Pada Perumahan Bukit Semarang Baru (BSB) City Di Semarang Jurusan Managemen Fakultas Ekonomi Universitas Pandanaran Semarang

Lamb W, Charles.et.al. 2008. Pemasaran. Edisi Pertama, Salemba Empat:Jakarta.

Lili Ekawati, H.Eddy Soegiarto, Eka Yudhyani, 2012. Pengaruh Harga Dan Promosi Terhadap Keputusan Membeli Air Mineral Aqua Di Samarinda Fakultas Ekonomi Universitas 17 Agustus 1945. Samarinda

Lupiyoadi, Rambat, (2013): Manajemen Pemasaran Jasa. Jakarta: Salemba. Empat.

Machfoedz, Mahmud. 2005. Pengantar Pemasaran Modern. Yogyakarta: Upp Amp. Ykpn

Madura Jeff, 2011, Pengantar Bisnis, Edisi Pertama, Jakarta : Salemba Empat.

Molan, Benyamin. 2005. Manajemen Pemasaran. Jakarta: Indeks Kelompok Media

Muanas, Ahmad, 2014. Pengaruh Produk, Harga Dan Promosi Terhadap Keputusan Pembelian Mobil Buana Indomobil Trada”. Sekolah Tinggi Ilmu Ekonomi Indonesia (Steisia) Surabaya

Muhammad Gigih Made P Pengaruh Promosi Dan Harga Terhadap Keputusan Pembelian Surat Kabar Harian Suara Merdeka

Mulyana, Slamet. (2009). Perilaku Konsumen. Artikel ini tersedia di situshttp://wsmulyana.wordpress.com/200 9/01/09/perilaku-konsumen/( Januari 2018)

Nur Indrianto dan Bambang Supomo, 2002..Metodologi Penelitian.Yogyakarta: BPFE

Peter J. Paul dan Jerry C. Olson. 2010. Perilaku konsumen dan strategi pemasaran. Edisi Sembilan. Buku 2.penerbit salemba empat.jakarta.
Rahman, Abdul. 2010. Panduan Pelaksanaan administrasi Perpajakan untuk Karyawan, Pelaku Bisnis, dan Perusahaan. Bandung: Nuansa

Saladin, Djaslim, 2013. Manajemen Pemasaran.Bandung: Linda Karya

Schiffman, L, G.dan,L. L. Kanuk.2009. Persepsi kualitas, Consumer Behavior. New Jersey: Perason Prestice Hall.

Siti Azizah "Pengaruh Produk, Harga Dan Promosi Terhadap Keputusan Konsumen Dalam Pembelian Rumah Tipe 36 Pada PT Usratu Busri Kota Pontianak. Universitas Muhammadiyah Pontianak

Siti Nurhayati, 2017. Pengaruh Citra Merek, Harga Dan Promosi Terhadap Keputusan Pembelian Handphone Samsung Di Yogyakarta Akademi Manajemen Administrasi YPK Yogyakarta

Sugiyono. 2014. Statistika Untuk Penelitian. CV.ALFABETA: Bandung

Sulistyo Joko, 2012.6 Hari Jago SPSS.Jakarta Sutisna. 2003, Perilaku Konsumen \& Komunikasi Pemasaran, Cetakan Ketiga, Bandung: PT Remaja Posdakarya.

Stanton, William J, 2004, Prinsip Pemasaran, Edisi Revisi Erlangga, Jakarta

Suryana, 2011. Kewirausahaan Pedoman Praktis: Kiat dan Proses Menuju Sukses, Edisi Ketiga,Penerbit Salemba, Jakarta

Suzy Widyasari dan Erna Triastuti Fifilia Analisis Pengaruh Produk, Harga, Promosi Dan Lokasi Terhadap Keputusan Pembelian Rumah ( Studi pada Perumahan Graha Estetika Semarang) Fakultas Ekonomi Universitas Stikubank Semarang

Swastha, Basu.2010.Manajemen Pemasaran: Analisa Perilaku Konsumen,Edisi pertama, cetakan keempat, Penerbit: BPFE, Yogyakarta

Swastha, Basu.2008. Manajemen Pemasaran. Edisi Kedua. Cetakan Kedelapan. Jakarta: Penerbit Liberty

Swastha, Basu dan T. Hani Handoko, 2008, Manajemen Pemasaran, Analisa Perilaku 
Konsumen, edisi pertama, cetakan keempat, Penerbit : BPFE, Yogyakarta

Swastha, Basu dan Irawan,2005,Asas-asas Marketing, Liberty, Yogyakarta.

Tjiptono, Fandy, 2012. Strategi Pemasaran, Edisi ke dua. Yogyakarta: Andi. 2008. Strategi Bisnis

Pemasaran. Andi. Yogyakarta. 2014 Total Quality Service. Penerbit Andi, Jogjakarta

Yulya Citra Sutra Syah, 2015 Pengaruh Produk, Harga Dan Lokasi Terhadap Keputusan Pembelian Perumahan Di Kota PadangDengan Keluarga Sebagai Variabel Pemoderasi (Studi Kasus Pada PT Hati Prima Griya Elok. Magister Sains Manajemen Program Pascasarjana Universitas Bung Hatta

https://beritagar.id/artikel/gaya-

hidup/indahnya-punya-rumah-sendiridan-layak-huni

https://www.rumah.com/beritaproperti/2016/12/142694/aturankepemilikan-rumah-semakin-mudah-di2017

https://keuangan.kontan.co.id/news/kpr-bankbesar-kian-mekar https://bisnis.tempo.co/read/1063254/penyalur an-kpr-bank-mandiri-di-2017-sebesar-rp397-triliun

https://keuangan.kontan.co.id/news/bankmandiri-percepat-proses-pengajuan-kpr 